\title{
Call for Papers, Issue 1/2023
}

\section{The Impact of the Business Process Model and Notation}

\author{
Kathrin Figl • Roman Lukyanenko $\cdot$ Jan Mendling $\cdot$ Gregor Polančič
}

Published online: 2 March 2021

(C) Springer Fachmedien Wiesbaden GmbH part of Springer Nature 2021

\section{Special Issue}

Initially published in 2004 by the Business Process Modeling Initiative (BPMI), the Business Process Modeling Notation (BPMN) was designed with the goal to provide a visual language that is understandable by different stakeholder groups who design, manage and implement business processes (BPMI 2004). The standardization of the notation led to an integration and consolidation of business process modeling concepts and tools. BPMN found immediate uptake by industry and academia, and was adopted by the Object Management Group (OMG) in 2006.

The specification of BPMN 2.0 was released by the OMG in 2011. This updated version builds upon an integrated meta-model with precisely defined semantics and a native XML-based interchange format. Due to these changes of the scope, BPMN 2.0 was renamed Business Process Model and Notation. In 2013, BPMN 2.0.1 was released as ISO/IEC 19510:2013 standard with the objective to "create a standardized bridge for the gap between the business process design and process implementation." This most recent version continues to be widely used in research and practice.

\section{K. Figl}

University of Innsbruck, Innsbruck, Austria

R. Lukyanenko

HEC Montréal, Montréal, Canada

J. Mendling ( $\bowtie)$

Vienna University of Economics and Business, Vienna, Austria

e-mail: jan.mendling@wu.ac.at

G. Polančič

University of Maribor, Maribor, Slovenia
So far, BPMN has had an impact at various levels. Most obvious is its standing as a de facto standard for business process modeling in practice (Recker 2010; Chinosi and Trombetta 2012; Leopold et al. 2015). Its uptake in research can be easily traced based on the immense amount of papers that at least mention BPMN, the number of which ranges above 50,000. However, there are many facets of this success that are less clear and which raise interesting research questions. It is the ambition of this special issue to investigate some of the antecedents and consequences of the standardization of BPMN.

\section{Invited Contributions}

It is the goal of this special issue to investigate BPMN development, uptake, usage, and impact. This means that we are interested in papers that present qualitative or quantitative research, meta-studies, or descriptive studies about BPMN's uptake and how its success came about over the years. This implies that we are specifically interested in the roles that various actors played throughout the journey of BPMN and how BPMN shaped the journey of these actors, let them be individuals, groups, organizations, communities, or markets. Note that this special issue is not interested in research in which BPMN is just used for some purpose. Key for a submission to this special issue is research with a focus on how actors do things in relation to BPMN and which kind of intended and emerging effects this has brought about.

In the following, we present a list of research questions that we believe to be highly relevant for this special issue. Note that this list is not exhaustive, but should help clarifying which kind of submissions we specifically embrace. 
- How did the process of standardizing BPMN unfold? Who was involved, what was their agenda, which decisions were taken, and why? Note that similar questions have been researched for Internet standards (Lyytinen and King 2006; Nickerson and zur Muehlen 2006).

- How did the process of BPMN uptake unfold among vendors? Which companies were fast to jump on it for which reasons, and which initially avoided it and why?

- How did the process of BPMN uptake unfold among different groups of actors? Why did some embrace it, which benefits did they expect, and which actual benefits materialized?

- How did the process of BPMN uptake unfold among researchers? Which benefits were expected, and which benefits materialized eventually?

- How is BPMN actually used? How has BPMN been adopted and used in organizations at a larger scale? Which kind of results has it provided? Note that similar questions have been researched for UML in the past (e.g., Dobing and Parsons 2006; Petre 2013).

- How did the market of BPMN-related products and services develop and evolve? What were the important factors and circumstances for these developments?

- How did different actors take decisions on adopting and using the BPMN standard? In which way did institutional factors such as coercive, mimetic, and normative forces play a role (DiMaggio and Powell 1983)?

- To which extent did the prospective benefits of BPMN as stated in the specification actually materialize in practice, and on which factors and circumstances do they depend?

- Which kind of benefits does BPMN provide for analysts in their journey from novices to experts? To which extent does BPMN help analysts do a good job?

- What conclusions does the development of BPMN over the last 20 years offer regarding the relevance and benefits of conceptual modeling in general? What are interesting and surprising applications of BPMN in other domains (e.g., BPMN has been used in chemistry), and what can we learn from them?

- To what extent has BPMN been adopted in individual companies at the group, division, and enterprise level, and which antecedents and consequences have been connected with this adoption?

- How did communities of practice around BPMN develop and which kind of benefits have they provided to their members?

- Which role did the availability of BPMN play for various startups? Which antecedents and consequences did the availability of BPMN bring along for these startups?
- How can we study and measure the uptake of BPMN in a reliable way? What does the overall population of persons and companies that are associated with BPMN look like?

- What are the perspectives of economics on BPMN? How can we measure the larger impact of BPMN at a macro level? Which economic theories reveal insights into BPMN usage?

- What would a theoretical model of conceptual modeling language success look like (Moody 2003; Recker 2012)?

- How does BPMN adoption, usage, and impact relate to other standards of system analysis and design, and to different types of information systems and tools?

- What is the uptake and impact of BPMN for supporting technology trends such as process mining, digital transformation, analytics, artificial intelligence, machine learning, blockchain, internet of things, etc. (Recker et al. 2021)?

\section{Submission Guidelines}

Please submit papers by 7 January 2022 at the latest via the journal's online submission system (http://www.editor ialmanager.com/buis/). Please observe the instructions regarding the format and length of contributions to Business \& Information Systems Engineering (BISE). Papers should adhere to the general BISE author guidelines (http:// www.bise-journal.com/author_guidelines).

All papers will be reviewed anonymously (double-blind process) by at least two referees with regard to relevance, originality, and research quality. Directly after the first submission deadline, the special issue editors will screen the papers for their potential. We will make use of desk rejects for papers not fitting the focus of the special issue, even if they might look promising as a general submission.

\section{Deadlines}

Submission Deadline: 07 January 2022

Author Notification 1: 15 March 2022

Completion Revision 1: 15 May 2022

Author Notification 2: 01 July 2022

Completion Revision 2: 01 September 2022

Print publication: February 2023 


\section{References}

BPMI (2004) Business process modeling notation, (1.0). http://www. bpmi.org/bpmn-spec.htm. Accessed 7 Feb 2021

Chinosi M, Trombetta A (2012) BPMN: an introduction to the standard. Comput Stand Interfaces 34:124-134

DiMaggio PJ, Powell WW (1983) The iron cage revisited: institutional isomorphism and collective rationality in organizational fields. Am Soc Rev 48(2):147-160

Dobing B, Parsons J (2006) How UML is used. Commun ACM 49(5):109-113

Leopold H, Mendling J, Günther O (2015) Learning from quality issues of BPMN models from industry. IEEE Softw 33(4):26-33

Lyytinen K, King JL (2006) Standard making: a critical research frontier for information systems research. MIS Q 30:405-411

Moody DL (2003) The method evaluation model: a theoretical model for validating information systems design methods. In:
Proceedings of the European conference on information systems. https://aisel.aisnet.org/ecis2003/79/

Nickerson JV, zur Muehlen M (2006) The ecology of standards processes: insights from internet standard making. MIS Q 30:467-488

Petre M (2013) UML in practice. In: 35th international conference on software engineering. IEEE, pp 722-731

Recker J (2010) Opportunities and constraints: the current struggle with BPMN. Bus Process Manag J 16(1):181-201

Recker J (2012) BPMN research: what we know and what we don't know. Int Workshop Bus Process Model Not. Springer, Heidelberg, pp 1-7

Recker J, Lukyanenko R, Jabbari M, Samuel BM, Castellanos A (2021) From representation to mediation: a new agenda for conceptual modeling research in a digital world. MIS Q 45(1) 